\title{
Antibody to coliform antigens in urine samples from patients with symptoms of urinary tract infection
}

\author{
H McKENZIE, D N YOUNG \\ From the Department of Medical Microbiology, Ninewells Hospital and Medical School, Dundee, and \\ Bacteriology Department, Stracathro Hospital, Brechin, Angus, Scotland
}

SUMMARY An enzyme linked immunoadsorbent assay (ELISA) was used to detect IgG, IgM, and IgA antibody in urine to a crude antigenic mixture prepared from six arbitrarily chosen strains of common coliform urinary pathogens. In a group of patients with symptoms of urinary tract infection 24 of $80(30 \%)$ urine samples were positive on culture by conventional methods, 58 of 80 $(72.5 \%)$ were positive for polymorphs on microscopy, and 72 of $80(90 \%)$ were positive for antibody by ELISA. Secretory component was detected in 28 of 80 (35\%) samples, and this is consistent with local antibody production. The results show that antibody can be detected in a wide range of urine samples using a simple antigen mixture, and this may form the basis of a useful test to diagnose urinary tract infection.

Antibody has been found in urine during the course of urinary tract infections, either free in the urine, ${ }^{12}$ or combined with antigen to form bacteria coated with antibody. ${ }^{3}$ The importance of combined antibody has been extensively investigated, ${ }^{4}$ but much less is known about free urinary antibody. This may be because of the difficulties in selecting an appropriate antigen from the wide range available. Most workers have measured antibody in individual urine samples specific for 0 antigen, prepared from the infecting strain of Escherichia coli. This method is suitable in a research laboratory where small numbers of specimens are tested, but it cannot be used routinely for large numbers of specimens, nor can it be applied to specimens that are negative on culture.

We have tried to develop the technique so that it may be applied to all urine samples by using a mixed antigen to bind antibody of a wide range of specificities. It would be impractical to include all possible 0 antigens in such a mixture, but many other antigens are present in coliform organisms, ${ }^{5}$ and there is likely to be a wide area of cross reaction among different strains and species. Therefore, urinary antibody might be detected in most infections by using a comparatively simple antigen mixture that includes cross reacting or shared determinants. This report describes the use of an enzyme linked immuno-

Accepted for publication 3 February 1987 adsorbent assay (ELISA) to measure urinary antibody to a crude but standardised antigen prepared from six coliform organisms in symptomatic patients and controls. The organisms selected were arbitrarily chosen strains of coliforms routinely isolated from urine. Samples were also examined by culture and microscopy.

\section{Patients and methods}

Mid stream specimens of urine were obtained from 85 patients, and brief clinical details were supplied by general practitioners. Most patients had at least two of three symptoms - dysuria, frequency, and urgency-but nine had loin pain, fever, or rigors, indicating upper urinary tract infection. One patient had taken an antibiotic during the week before the samples were collected. Most of the specimens were processed on the day of collection, but no special arrangements were made for rapid transport of specimens to the laboratory. Patients with catheters were excluded from the study.

Control specimens were obtained from 40 healthy students ( 18 women and 22 men), who had no history of urinary tract infection during the previous four weeks.

\section{CULTURE AND MICROSCOPY}

The specimens of urine were collected in Boricon containers (Medical Wire and Equipment, Corsham, 
Wiltshire, England) and cultured by inoculation on to MacConkey agar with a Bacteriuritest filter strip (Mast Laboratories, Bootle, Merseyside, England) according to the manufacturer's instructions. A pure growth of sufficient quantity of a lactose fermenting organism was recorded as $>10^{5}$ coliform bacilli $/ \mathrm{ml}$. Samples yielding $>10^{5}$ organisms $/ \mathrm{ml}$ of a mixture of three or more organisms were discarded as contaminated, and samples yielding $<10^{5}$ organisms $/ \mathrm{ml}$ were designated culture negative. Microscopy was performed by examination of uncentrifuged specimens of urine at a magnification of 400 in a Kova multichamber slide (Kova ICL Scientific, 18249 Euclid, Fountain Valley, California, USA). Pyuria was defined as one or more polymorphs per 20 high power fields. All samples were stored at $4^{\circ} \mathrm{C}$ while being studied.

PREPARATION OF ANTIGEN

All organisms were cultured on nutrient agar (Oxoid Ltd, Basingstoke, Hampshire, England) for 48 hours at $37^{\circ} \mathrm{C}$, except for Bacteroides fragilis, which was cultured on blood agar (Oxoid) anaerobically for 48 hours. The growth from two agar plates was harvested, and suspended in $0 \cdot 15 \mathrm{M}$ sterile saline, and centrifuged at $3000 \mathrm{~g}$ for 15 minutes. The pellet was resuspended in $5 \mathrm{ml} 0 \cdot 15 \mathrm{M}$ sterile saline, and the concentration adjusted until a 1/10 dilution had an extinction of 0.25 at $540 \mathrm{~nm}$. This concentration was found to be the best for coating plates with antigen. The suspension was then heated for 30 minutes at $100^{\circ} \mathrm{C}$. Antigen prepared in this way was used directly in absorption experiments, or mixed $9 / 1 \%(\mathrm{v} / \mathrm{v})$ with $0.5 \mathrm{M}$ carbonate-bicarbonate buffer, $\mathrm{pH} 9.6$, and used to coat assay plates.

\section{MIXED COLIFORM ANTIGEN}

Six coliform organisms were prepared, and then mixed together in equal volumes before being used to coat plates. Five of the organisms were identified by API 20E (API System SA, 38390 Montalieu Vercieu, France) as $E$ coli (three strains), Klebsiella aerogenes, and Citrobacter freundii. The remaining organism was identified as Proteus mirabilis by routine biochemical tests. These were selected arbitrarily from routine urine isolates to represent a range of common urinary pathogens. The three strains of $E$ coli showed minor variations in their biochemical profiles on the API system.

\section{ENZYME LINKED ANTIHUMAN}

IMMUNOGLOBULIN CONJUGATES

Alkaline phosphatase-labelled, affinity purified, antihuman IgG, IgA, and IgM (Sigma Chemical Co, Poole, Dorset, England) were diluted $1 / 400$ in $0.05 \mathrm{M}$ phosphate buffered saline, $\mathrm{pH} 7 \cdot 4$, to which $0.01 \%$ (v/v) Triton X-100 had been added (PBST). Anti- 욤 human antisecretory component (Seward Laborato- 음 ries, London) was conjugated to alkaline phosphatase $\stackrel{\text {. }}{\Rightarrow}$ (Sigma) by the method of Voller, Bidwell, and $\underset{\vec{F}}{\overrightarrow{7}}$ Bartlett. ${ }^{6}$ This was used in the antibody assay at ato dilution of $1 / 100$ in PBST.

\section{ANTIBODY ASSAY}

Nunclon flat bottomed 96 Microwell plates (Gibco Ltd, Paisley, Scotland) were coated with $100 \mu 1$ of ${ }^{\infty}$ antigen preparation in each well by incubation for $\vec{\circ}$ two hours at $37^{\circ} \mathrm{C}$, and 16 hours at $4^{\circ} \mathrm{C}$. Each well was washed three times with PBST and then incu- $\stackrel{\omega}{\circ}$ bated before use with $100 \mu \mathrm{l}$ of $1 \%(\mathrm{w} / \mathrm{v})$ bovine serum albumin (Fraction V, Sigma) in $0.05 \mathrm{M}$. carbonate-bicarbonate buffer, $\mathrm{pH} 9 \cdot 6$, for two hours at $37^{\circ} \mathrm{C}$. After three further washes $100 \mu \mathrm{l}$ of each urine specimen was dispensed in duplicate and the plate incubated at $37^{\circ} \mathrm{C}$ for one hour. After washing $\mathrm{O}$ $100 \mu \mathrm{l}$ of anti-immunoglobulin conjugate was added to each well and the incubation and washing stages repeated. $100 \mu \mathrm{l}$ of a $1 \mathrm{mg} / \mathrm{ml}$ solution of p-nitrophenyl phosphate (Sigma) in 0.05 M glycine-sodium $\vec{\bullet}$ hydroxide buffer, $\mathrm{pH} 10 \cdot 2$, was added, and the colour $\cong$ in each well measured at $410 \mathrm{~nm}$ after 30 minutes at room temperature. Each assay plate included a blank control well to which no urine was added, as well as a duplicate well containing a positive reference sample.

\section{ABSORPTION EXPERIMENTS}

The specificity of the antibody measured was $\overrightarrow{\overrightarrow{0}}$ investigated by preincubation of urine samples with $\frac{3}{3}$ equal volumes of a suspension of mixed coliform antigen or of other antigen preparations. The latter were prepared from single strains of Staphylococcus saprophyticus, Streptococcus faecalis, and Bacteroides frag-? ilis. After incubation of urine and antigen suspension for 60 minutes at $37^{\circ} \mathrm{C}$ each mixture was centrifuged at $3000 \mathrm{~g}$ for 15 minutes and the supernatant assayed for IgG antibody to mixed coliform antigen as before. Control samples were also mixed with an equal vol- 은 ume of $0.15 \mathrm{M}$ sterile saline and assayed after incubation.

\section{Results}

The results of all antibody determinations were $\stackrel{N}{\omega}$ expressed as the average extinction at $410 \mathrm{~nm}$ of duplicate results for each sample. The results were $\circ$ standardised against the values obtained for the posi- $\mathbb{D}$ tive reference sample in the appropriate assay run.? Urine specimens from symptomatic patients were des- $\frac{T}{3}$ ignated positive for antibody in any one immunoglobulin class if they produced a reading greater than the corresponding mean plus two SD for the control samples. 
Table 1 Classification of urine specimens from 85 symptomatic patients by culture and microscopy

\begin{tabular}{lc}
\hline Classification & No tested \\
\hline Coliform culture positive & 24 \\
Culture negative with pyuria & 34 \\
Culture negative without pyuria & 22 \\
Contaminated specimens & 5 \\
\hline
\end{tabular}

\section{STATISTICAL METHODS}

The significance of differences in antibody levels between groups was tested by the Mann-Whitney $U$ test, and of the different frequency of IgM in symptomatic groups by the $\chi^{2}$ test.

\section{CULTURE AND MICROSCOPY}

After culture and microscopy urine samples from 85 patients with clear symptoms of urinary tract infection were classified (table 1). Five samples were discarded because they were contaminated. Only 24 of the remaining 80 samples $(30 \%)$ were positive on culture, and all contained polymorphs. Samples which were negative on culture were divided into those that showed pyuria and those that did not. All control samples were negative on culture and microscopy.

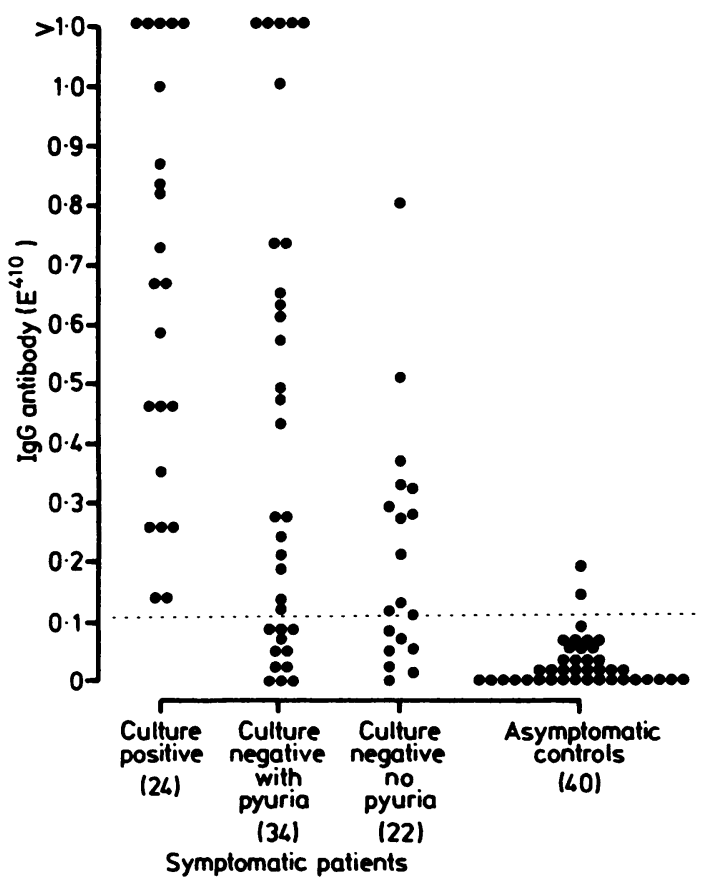

Fig 1 IgG antibody ( $E^{410}$ ) to mixed coliform antigen in urine samples from patients and controls. Broken line = mean ( + $2 S D)$ of control values.

\section{URINARY ANTIBODY}

Antibody to the mixed coliform antigen was measured in all except the contaminated samples, and also in samples of urine from $\mathbf{4 0}$ healthy volunteers. No significant differences were found between samples from male and female volunteers, and the control results were therefore pooled for further analysis. Fig 1 shows that levels of IgG antibody to the mixed coliform antigen were significantly raised in all symptomatic groups when compared with those of asymptomatic controls $(p<0.001)$. Similar results were obtained for other immunoglobulin classes, and fig 2 shows the overall immunoglobulin class distribution of antibody in different groups of symptomatic patients. In all, 72 samples $(90 \%)$ were positive for antibody in at least one immunoglobulin class, including all positive on culture samples and 48 of the remaining 56 samples that were culture negative. The immunoglobulin profile was not identical in all groups, however. Samples positive for all three immunoglobulins tested were predominant in the culture positive samples and those negative on culture and showing pyuria, while the combination of $\mathrm{IgG}$ and IgA was most common in those negative on culture but without pyuria. The number of samples in the latter group containing IgM, either alone or in combi-

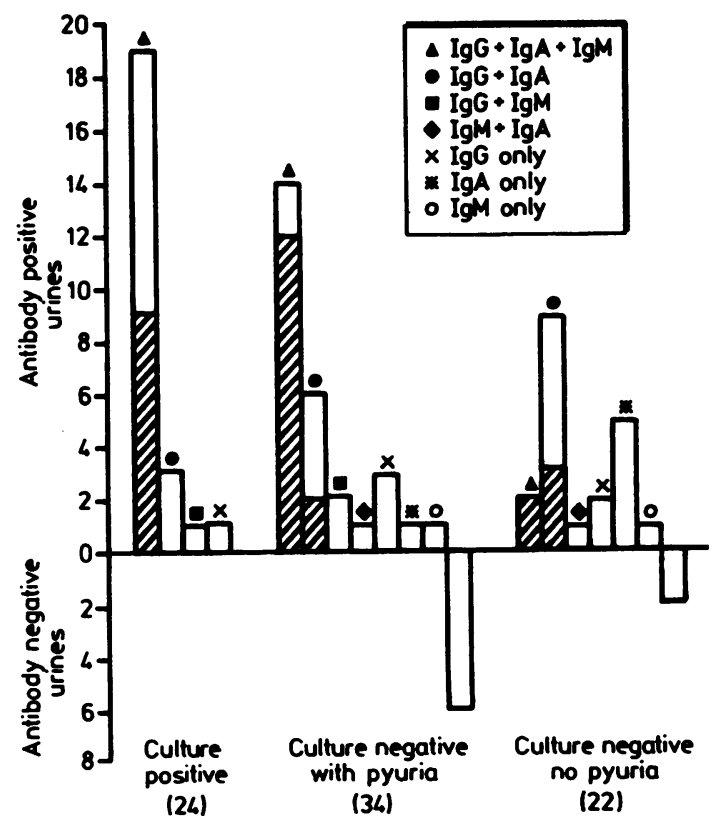

Fig 2 Immunoglobulin class distribution of urinary antibody to mixed coliform antigen in different groups of symptomatic patients. Cross hatched areas show No of samples in each category containing secretory component. 
Table 2 IgG antibody $\left(E^{410}\right)$ to mixed coliform antigen after preincubation with mixed coliform antigen or other unrelated antigens

\begin{tabular}{llllll}
\hline & & \multicolumn{2}{l}{ Antigen used for preincubation } \\
\cline { 2 - 5 } Urine sample & Control & $\begin{array}{l}\text { *Mixed coliform } \\
\text { antigen }\end{array}$ & S saprophyticus & S faecalis & B fragilis \\
\hline 1 & 1.03 & 0.21 & 0.97 & 0.98 & 1.03 \\
2 & 0.36 & 0.03 & 0.38 & 0.34 & 0.34 \\
3 & 1.76 & 0.51 & 1.59 & 1.55 & 1.58 \\
4 & 1.36 & 0.15 & 1.28 & 0.98 & 1.23 \\
5 & 0.51 & 0.06 & 0.44 & 0.39 & 0.39 \\
6 & 0.42 & 0.04 & 0.39 & 0.41 & 0.39 \\
\hline
\end{tabular}

*Significantly lower than control values, $\mathrm{p}<0.05$.

nation with other immunoglobulin classes, was significantly lower than that in the other two symptomatic groups $(p<0.01)$. The culture negative samples with no pyuria also contained the largest number of specimens with IgA alone. Secretory component was detected in 28 of $80(35 \%)$ samples.

\section{ANTIBODY SPECIFICITY}

The specificity of the measured antibody was tested by assay of selected urines following absorption with mixed coliform antigen, or with antigens prepared from other unrelated organisms. Table 2 shows that IgG antibody to mixed coliform antigen was not absorbed by antigens prepared from $S$ saprophyticus, $S$ faecalis, and $B$ fragilis, but was absorbed significantly by preincubation with the mixed coliform antigen $(\mathrm{p}<0.05)$.

The amount of reactivity of urinary antibody to individual coliform organisms was also measured. Five culture positive urine specimens were tested for the presence of $\mathrm{IgG}$ antibody to each of the corresponding five coliform isolates. Table 3 shows that while all five antigens bound antibody from all five urine samples, antibody in only one of the five specimens reacted most strongly to its own isolate. The effectiveness of individual components of the mixed coliform antigen in binding antibody was studied by

Table 3 IgG antibody ( $E^{410}$ ) in five coliform culture positive urine samples

\begin{tabular}{llllll}
\hline \multirow{2}{*}{$\begin{array}{l}\text { Urine } \\
\text { sample }\end{array}$} & \multicolumn{5}{l}{ Antigen preparation } \\
\cline { 2 - 6 } & $I$ & 2 & 3 & 4 & 5 \\
\hline 1 & 0.13 & 1.21 & 0.55 & 0.33 & 0.86 \\
2 & 0.23 & 0.36 & 0.18 & 0.20 & 0.27 \\
3 & 0.48 & 0.70 & 0.44 & 0.33 & 1.19 \\
4 & 0.59 & 0.99 & 0.22 & 0.37 & 0.26 \\
5 & 0.31 & 0.67 & 0.48 & 0.43 & 0.44 \\
\hline
\end{tabular}

testing three culture and three culture negative urine samples against antigens prepared from each component organism. Table 4 shows that each organism bound antibody from all six urine specimens, although there was considerable variation in the pattern of reactivity of each individual sample. No single organism was clearly more effective than the others at binding antibody.

\section{Discussion}

Antibody to a mixed coliform antigen was detected in a high proportion $(90 \%)$ of urine samples from patients with symptoms of urinary tract infection, many of them negative on culture when tested by conventional methods. The specificity of the antibody for coliform antigens is clearly shown by the results of the absorption experiments, and urine samples positive for antibody reacted with antigens prepared from a wide range of coliform organisms. These findings support the hypothesis that there are common antigens shared by coliform organisms, and that a simple representative mixture may be effective in binding antibody that is produced in response to any single coliform pathogen. The components of the antigenic mixture used have not been investigated, but undoubtedly include 0 antigens as well as others such as $\mathrm{H}, \mathrm{K}$, and fimbrial antigens. Further studies are required to establish which antigens are important in the selection of organisms for the antigen mixture, but the present results suggest that it is not essential to include all 0 antigens.

In previous studies samples have been tested for antibody to the patient's own infecting organism. We have found, however, that the patient's own isolate is often less effective than other organisms at binding antibody. This may be the result of antibody to the predominant antigens of the infecting organism being absorbed in the urine, with little remaining free for in vitro detection. Furthermore, the infecting organism 
Table 4 IgG antibody $\left(E^{410}\right)$ to separate components of mixed coliform antigen in six urine samples

\begin{tabular}{|c|c|c|c|c|c|c|c|}
\hline \multirow{2}{*}{$\begin{array}{l}\text { Urine } \\
\text { sample }\end{array}$} & \multirow[b]{2}{*}{ Result of culture } & \multicolumn{6}{|c|}{ Antigen preparation } \\
\hline & & $E$ coli (I) & E coli (2) & E coli (3) & K aerogenes & C freundii & $P$ mirabilis \\
\hline 1 & $10^{5}$ coliform bacilli $/ \mathrm{ml}$ & $0 \cdot 26$ & $0 \cdot 11$ & $0 \cdot 19$ & $0 \cdot 18$ & 0.97 & 0.26 \\
\hline 2 & $10^{5}$ coliform bacilli/ml & 0.51 & 0.99 & 1.45 & $>1.99$ & 1.46 & 0.22 \\
\hline 3 & $10^{5}$ coliform bacilli $/ \mathrm{ml}$ & 0.25 & 1.58 & 0.22 & 0.25 & $0 \cdot 19$ & $0 \cdot 18$ \\
\hline 4 & Negative & $>1.99$ & 1.59 & 0.38 & $0 \cdot 35$ & 0.52 & $0 \cdot 24$ \\
\hline 5 & Negative & $1 \cdot 33$ & 0.14 & 0.31 & $0 \cdot 31$ & 0.26 & $0 \cdot 18$ \\
\hline 6 & Negative & $0 \cdot 19$ & $1 \cdot 15$ & $0 \cdot 12$ & 0.33 & 0.57 & $0 \cdot 10$ \\
\hline
\end{tabular}

can change antigenically during the course of an infection, ${ }^{7}$ and the antibody may be directed against antigens which are no longer present when the organism is cultured. Finally, the antibody measured may not represent a specific response to the invading organism, but instead, may represent a leakage of existing serum antibody through the inflamed mucosa of the urinary tract. A local antibody response probably does take place, however, within the urinary tract, ${ }^{2}$ and this is consistent with the presence of secretory component in many of the samples that we tested. As the antibody measured may therefore be a combination of a local specific response and preexisting serum antibody, it is not possible to conclude that the finding of coliform antibody in a urine sample always proves the existence of a coliform urinary tract infection.

Other authors have found $\operatorname{IgG}$ and $\operatorname{IgA}$ antibody in urine samples, but IgM was a less common finding. ${ }^{2}$ In contrast, we often found IgM in two of the three symptomatic groups. Few of the samples that were culture negative with no pyuria contained IgM, and this group had the largest number of samples containing IgA alone. The apparent absence of pyuria in this group may have been due to a delay in examination of a few specimens, but the variation in immunoglobulin profile suggested a qualitative difference between this and other symptomatic groups. This group may have a different stage or type of infection, perhaps more superficial and limited to the mucosa. This would be consistent with the production of IgA antibody, with less likelihood of IgM leakage from blood. IgA is not important in complement fixation, and therefore would not provide a chemotactic signal for polymorphs to migrate to the site of infection. Further studies are required to establish whether patients in this group show any important clinical differences from other symptomatic patients.

The difference between the number of positive cultures and positive antibody results in our study is striking $(30 \% v 90 \%)$. The validity of accepting only $10^{5}$ organisms $/ \mathrm{ml}$ or more as diagnostic of bacteriuria is increasingly being questioned, and in symptomatic patients a much lower bacterial count may be acceptable. $^{89}$ At this lower threshold, however, the distinction between contamination and infection is more difficult, and there is a need for an indicator of host response to make it easier. The presence of pyuria has been suggested ${ }^{8}$ but microscopy for polymorphs is labour intensive, and requires rapid examination of samples before the cells degenerate. Urinary antibody may be an alternative marker of the host's response to infection, and we may improve the accuracy of our diagnosis of urinary tract infections by using a more sensitive culture method, and by interpreting the findings in the light of urinary antibody titres. The ELISA that we used is suitable for automation and could easily be adapted for any laboratory. Measurement of urinary antibody may therefore be a useful screening test for infection, or an alternative to microscopy in the interpretation of results of culture. Further studies are in progress to assess its value to the clinician and to the microbiologist in the diagnosis and management of urinary tract infections.

We thank local general practitioners, the technical staff of the bacteriology department, Stracathro Hospital, Brechin, for their cooperation, and Dr D Parratt for helpful discussion. This work was partially supported by a grant from the University of Dundee.

\section{References}

1 Jodal U, Ahlstedt S, Carlsson B, Hanson LA, Lindberg U, Sohl A. Local antibodies in childhood urinary tract infection. A preliminary study. Int Arch Allergy Appl Immunol 1974;47:537-46.

2 Akerlund AS, Ahlstedt S, Hanson LA, Jodal U. Antibody responses in urine and serum against $E$ coli 0 antigen in childhood urinary tract infection. Acta Pathologica et Microbiologica Scandinavia [C] 1979;87:29-36.

3 Thomas VL, Shelekov A, Forland M. Antibody coated bacteria in the urine and the site of urinary tract infection. $N$ Engl $J$ Med 1974;290:588-90.

4 Giamarellou $H$. Antibody coated bacteria in urine: when, where and why? J Antimicrob Chemother 1984;13:95-9. 
5 Holmgren J, Eggerston G, Hanson LA, Lincoln $\mathrm{K}$. Immunodiffusion studies on $\mathrm{E}$. coli 1 . Identity of $\mathrm{O}, \mathrm{K}$ and $\mathrm{H}$ antigens in an 06 strain. Acta Pathologica et Microbiologica Scandinavia 1969;76:304-18.

6 Voller A, Bidwell DE, Bartlett A. Enzyme immunoassays in diagnostic medicine. Theory and practice. Bull WHO 1976;53:55-65.

7 Hanson LA, Ahlstedt S, Jodal U, et al. The host parasite relationship in urinary tract infections. Kidney Int [suppl] 1975;8:28-34.
8 Stamm WE, Counts GW, Running KR, Fihn S, Turck M, Holmes KK. Diagnosis of coliform infection in acutely dysuric women. N Engl J Med 1982;307:463-8.

9 Latham RH, Wong ES, Larson A, Coyle M, Stamm WE. Laboratory diagnosis of urinary tract infection in ambulatory women. JAMA 1985;254:3333-6.

Requests for reprints to: Dr H McKenzie, Department of Medical Microbiology, Ninewells Hospital and Medical School, Dundee DD1 9SY, Scotland. 